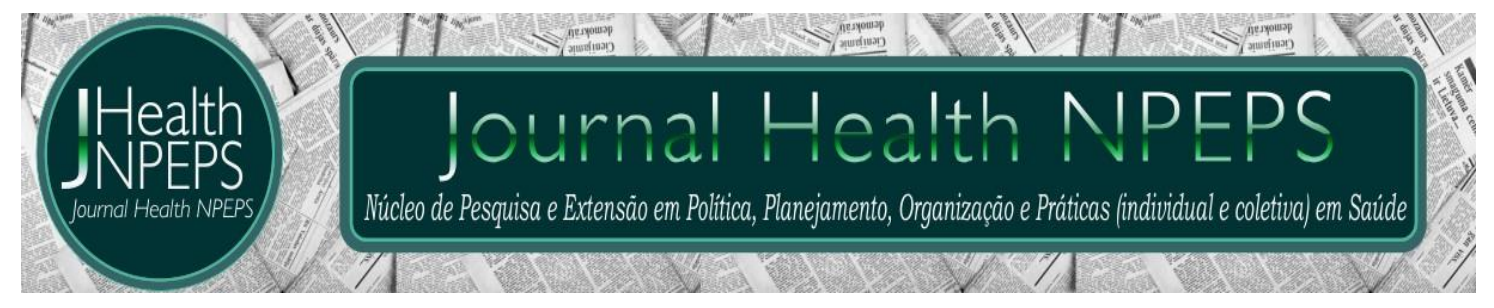

http://dx.doi.org/10.30681/25261010325111

EDITORIAL

\title{
Prática esportiva e exercício físico na prevenção e tratamento da dependência química
}

\section{Sports practice and physical exercise in prevention and treatment of chemical dependency}

\section{Práctica deportiva y ejercicio físico en la prevención y tratamiento de la dependencia química}

\section{João Alves de Moraes Filho', Poliany Cristiny de Oliveira Rodrigues², Riller Silva Reverdito ${ }^{3}$}

O uso de substâncias psicoativas não é algo novo no mundo, existindo na trama complexa da história da humanidade. Na contemporaneidade, tem sido considerado um problema de grande magnitude, pelas consequências negativas que ocasiona, quer seja nas relações sociais e dinâmicas familiares ${ }^{1}$ como aos impactos diretos à saúde e qualidade de vida do ser humano.

Um dos motivos que sustenta o uso e a utilização precoce dessas substâncias é a sensação de alento gerada frente ao mal-estar às renúncias impostas pela civilização, bem como ao possível alívio diante de múltiplos sofrimentos internos e a busca incessante por prazer e aceitação nos grupos².

\footnotetext{
${ }^{1}$ Educador Físico. Doutor. Professor da Faculdade de Ciências da Saúde da Universidade do Estado de Mato Grosso (UNEMAT). Campus de Cáceres. Cáceres, Mato Grosso, Brasil. E-mail: kimoxi.br@gmail.com ORCID ID: https://orcid.org/0000-0001-8466-8865

${ }^{2}$ Enfermeira. Doutora. Professora da Faculdade de Ciências da Saúde da Universidade do Estado de Mato Grosso (UNEMAT). Campus de Cáceres. Cáceres, Mato Grosso, Brasil. E-mail: polianyrodrigues@unemat.br ORCID ID: https://orcid.org/0000-0002-9225-8935

${ }^{3}$ Educador Físico. Doutor. Professor da Faculdade de Ciências da Saúde da Universidade do Estado de Mato Grosso (UNEMAT), Campus de Cáceres. Docente do Programa de Pós-Graduação em Educação Física da Universidade Federal de Mato Grosso (UFMT). Cáceres, Mato Grosso, Brasil. E-mail: rsreverdito@unemat.br ORCID ID: https://orcid.org/0000-0003-0556-9151
}

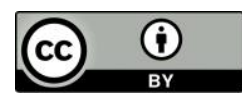

Este artigo está licenciado sob forma de uma licença Creative Commons Atribuição 4.0 Internacional, que permite uso irrestrito, distribuição e reprodução em qualquer meio, desde que a publicação original seja corretamente citada. 
A dependência dessas substâncias compromete várias dimensões da pessoa, indo dos sistemas vitais do organismo 3 às dimensões psicossociais. Neste aspecto, são observados facilmente dificuldades ou problemas na realização e desenvolvimento das atividades profissionais, estudos e convívio social favorável, aproximando ou fomentando situações de auto ou hetero violência.

Estudo com norte-americanos revela o acesso cada vez mais facilitado às drogas, em especial o álcool, tabaco e maconha ${ }^{4}$. No Brasil, também observa crescimento no consumo dessas substâncias, tanto de forma individualizada como cruzada $^{5}$, o que aumenta a preocupação em intervir junto à comunidade.

Nesse contexto, a prática esportiva e o exercício físico têm chamado atenção pela associação positiva com a prevenção e tratamento dessa problemática, tanto em caráter individual como coletivo, justamente pela potencialidade em agregar e inserir os indivíduos em grupos sociais e favorecer novas relações interpessoais. Além disso, outros benefícios ligados à saúde física e mental são propiciados, como a redução da gordura corporal, melhoria das funções cardíacas e pulmonares, capacidade físico-motora, aumento da autoestima e bem-estar, minimização de quadros de depressão e ansiedade, e motivação para dar início ou manter o processo de recuperação da dependência química ${ }^{6}$.

Estudo com dependentes químicos que realizaram sessões de exercícios físicos, identificou-se modificações significativas e assertivas na capacidade cognitiva e no desejo de consumir drogas, com destaque para a capacidade de atenção, memória e estado de humor, logo melhoria do estado geral e satisfação dos recuperandos ${ }^{7}$. Outros pesquisadores ${ }^{8}$ reforçam a importância da prática esportiva e exercício físico para a promoção de novos estilos de vida, em virtude dessa clientela apresentar comumente menores níveis de capacidade cardiorrespiratória e força muscular em relação a população em geral, em reflexo aos hábitos alimentares e rotina sedentária que possuem, e à exposição contínua às substâncias psicoativas e seus efeitos deletérios. 
No Brasil, o próprio Sistema Único de Saúde (SUS) tem valorizado e incentivado a integração dos profissionais de educação física na rede de atenção à saúde mental. Dessa forma, com o modelo de atenção orientado para a integralidade do cuidado à pessoa e fundamentado na ampliação do conceito de saúde - para além da ausência de doenças, as ações de tratamento, recuperação, reabilitação e ressocialização do dependente químico tem buscado no esporte e no exercício físico a aliança para fortalecer e complementar as estratégias terapêuticas disponibilizadas ${ }^{7-10}$, e como atividades da própria rotina de serviços de saúde voltadas à essa demanda, como por exemplo, nos Centros de Atenção Psicossocial (CAPS).

Por outro lado, a prática esportiva e o exercício físico de forma isolada não são suficientes para a assistência global ao dependente químico. Entretanto, podem possibilitar mudanças importantes, ao passo do dependente químico reconhecer tais atividades como apoio e suporte no enfrentamento da abstinência e na manutenção de sua sobriedade.

O desafio é, portanto, consolidar ações de prática esportiva e/ou exercício físico que sejam integradas ou complementares ao serviço de saúde, em uma concepção holística, já que a drogadição se trata de um complexo problema social e de saúde pública. Nessa conjuntura, discutir políticas públicas que garantam a interdisciplinaridade da assistência, a efetividade de serviços de base comunitária, bem como a formação interprofissional e permanente de recursos humanos em saúde, incluindo os profissionais de educação física, apresenta-se como estratégia real e de baixo custo para ampliar, alcançar e melhorar o cuidado as pessoas em situação de dependência química.

\section{REFERÊNCIAS}

1. Rosa MD. Adolescência: da cena familiar à cena social. Psicol USP. 2002; 13(2):227-41.

2. Schoen-Ferreira TH, Aznar-Farias M, Silvares EFM. Adolescência através dos séculos. Psicol teor pesqui. 2010; 26:227-34. 
3. Klaassen CD, Watkins JB. Fundamentos em Toxicologia de Casarett e Doull. Porto Alegre: AMGH; 2012.

4. Debnam KJ, Saha S, Bradshaw CP. Synthetic and Other Drug Use among High School Students: The Role of Perceived Prevalence, Access, and Harms. Subst use misuse. 2018; 53(12):2069-76.

5. IBGE. Pesquisa nacional de saúde do escolar : 2015. Rio de Janeiro: IBGE; 2016.

6. Rodrigues PC, Reverdito RS, Vieira PA. Praticar atividade física reduz ansiedade e depressão em estudantes universitários. In: Salud C. Convención Internacional de Salud; Havana, 2018.

7. Ferreira SE, Santos AKMS, Okano AH, Gonçalves BSB, Araújo JF. Efeitos agudos do exercício físico no tratamento da dependência química. Rev bras ciênc esporte. 2017; 39(2):123-31.

8. Malagodi BM, Greguol M, Serassuelo Junior H. Análise do equilíbrio corporal e aptidão física de indivíduos em tratamento para dependência química. Rev Bras Ativ Fís Saúd. 2018; 23(e0012):1-9.

9. Pratta EMM, Santos MA. O processo saúde-doença e a dependência química: interfaces e evolução. Psicol teor pesqui. 2009; 25(2):203-11.

10. Mendes MS. Dependência química e fortalecimento psicossocial pelas práticas esportivas. Estud psicol (Natal). 2017; 22(3):285-92.

Como citar este artigo: Moraes Filho JA, Rodrigues PCO, Reverdito RS. Prática esportiva e exercício físico na prevenção e tratamento da dependência química. Journal Health NPEPS. 2018 jul-dez; 3(2):304-307. 